\title{
A Decade of Jadelle Subdermal Implant Contraception in a Tertiary Health Institution in Port Harcourt, Southern Nigeria
}

\author{
E. O. Oranu, J. D. Ojule \\ Department of Obstetrics and Gynecology, University of Port Harcourt Teaching Hospital, Port Harcourt, Nigeria \\ Email: meetemma24@gmail.com
}

How to cite this paper: Oranu, E.O. and Ojule, J.D. (2018) A Decade of Jadelle Subdermal Implant Contraception in a Tertiary Health Institution in Port Harcourt, Southern Nigeria. Journal of Biosciences and Medicines, 6, 123-130.

https://doi.org/10.4236/jbm.2018.63010

Received: February 2, 2018

Accepted: March 27, 2018

Published: March 30, 2018

Copyright ( $) 2018$ by authors and Scientific Research Publishing Inc. This work is licensed under the Creative Commons Attribution International License (CC BY 4.0).

http://creativecommons.org/licenses/by/4.0/

Open Access

\begin{abstract}
Background: Jadelle, a long acting reversible progesterone contraceptive, has been in use in our centre for over 10 years and has not been comprehensively evaluated. Objectives: To determine the acceptance, efficacy, and safety profile associated with the use of Jadelle contraceptive implant in the University of Port Harcourt Teaching hospital, Port Harcourt. Methods: This is a 10-year retrospective study of clients who accepted and used Jadelle for contraception in the university of Port Harcourt Teaching Hospital (UPTH), Port Harcourt. The case files were retrieved and information on their socio demographic profile, source of information, side effects, failures and reason for removal were extracted using a proforma. Data were filled into a spread sheet, analyzed using SPSS version 21.0 and presented in tables of frequencies and percentages. Results: Within the period under review, March 2007 to February 2017, 569 clients used Jadelle out of the 3829 women who accepted and used modern contraceptive in the UPTH. The mean age of users was $33.7 \pm$ $4.2,536(94.2 \%)$ were multipara with a mean parity of $4.5 \pm 3.8$ while 541 (95.1\%) had secondary education and above. The major side effect was irregular vaginal bleeding $36(60.9 \%)$ while the main reason for removal of the device was expiration of method 272 (53.9\%). A pregnancy was recorded during this period giving a pearl index of 0.002 . Conclusion: Jadelle is a popular and a very effective means of contraception with increasing acceptance among our clients. The safety profile is high.
\end{abstract}

\section{Keywords}

Jadelle, High Efficacy, Safe, Port Harcourt

\section{Introduction}

The world population reached 7.3 billion as of mid-2015 [1]. Sixteen per cent 
(1.2 billion) of this reside in Africa [1] the continent with the second highest population, after Asia. The implications of population growth for universal access to reproductive health are particularly relevant to sub-Saharan Africa, a region that has experienced rapid population growth that is projected to remain above 2 percent per year through 2030 [2], the time period of the 2030 agenda for sustainable development. For instance, in 2015, sub-Saharan Africa failed to achieve universal reproductive health coverage, a target under Millennium Development Goals 5 aimed at improving material health [3].

The Nigerian population forecast by 2021 is put at 210 million [4] and a current fertility rate of 5.7. With the several challenges associated with over-population such as environmental pollution, rural-urban migration, and depletion of natural resources [5] [6], this fertility rate is worrisome. Adoption of population policies and fertility control by means of contraception is one acceptable route of controlling this population explosion [7]; noting that in spite of the relatively high fertility and population growth rates, low uptake of family planning services has been reported in several countries in the sub-Saharan Africa, especially in West-Africa. Contraceptive prevalence in 2015 was several times as high in Northern Africa and Southern Africa (53 percent and 64 percent, respectively) as in Middle Africa (23 percent) and Western Africa (17 percent) [8]. This relatively low prevalence has been associated with several challenges inherent in the delivery of family planning services in this sub-region.

Jadelle, a long acting reversible contraceptive option, consists of 2 sealed individual silicon rods; each is $2.5 \mathrm{~mm}$ in diameter and 4.3 in length, containing 75 mg levonorgestrel and is licensed for use for 5 years [9] [10]. It induces anovulation and hypotrophic endometrium by suppression of oestrogen maturation of the follicles and the endometrium; and thickens the cervical mucus [9] [11]. Jadelle is highly effective, safe and acceptable [12] [13] [14]. This long acting reversible contraceptive has minimal requirement for medical follow up once inserted. However, menstrual disturbances, compliant of weight gain and requirement for trained personnel for its insertion/removal remained issues to be sorted out in a poor resource setting like ours.

It is with these challenges in mind, coupled with the absence of enough data on the experience with Jadelle usage that this study was conceived. It is hoped that with the availability of more information on Physicians' experiences on Jadelle usage, more could be done in tackling the difficulties associated with uptake of contraceptive services in our environment particularly and Nigeria in general.

\section{Methodology}

This is a retrospective descriptive study of 569 clients who accepted to use Jadelle for contraception at the UPTH family planning clinic between March $1^{\text {st }}$, 2007 and February $28^{\text {th }}, 2017$. The ethical clearance for this study was given by the ethical committee. 
Trained family planning counselors (Nurses and physicians) counsel clients on the various modern contraceptive methods (implants, intrauterine device, injectable progestogen, oral contraceptives, bilateral tubal ligation) and guided them to make informed choices of method suitable for them. Medical history is taken and a clinical examination is performed. A urine analysis is done as well as a pregnant test to exclude pregnancy. Those who were pregnant, severely hypertensive diabetic, have unexplained vaginal bleeding or did not give consent were excluded from receiving Jadelle. Barrier contraceptives were excluded in this study as there was no recorded evidence on their follow up hence its use for the purpose of contraception was not guaranteed.

Case records of clients on contraception are kept in the family planning record section. Their socio demographic characteristics, source of information, side effects, failures and reasons for removal of implant for clients on Jadelle extracted from their case files and the data entered into statistical package for social sciences (SPSS) version 21.0 spread sheet for analysis and result presented in tables in frequencies and percentages.

\section{Result}

In the period under review 2007-2017, a total of three thousand eight hundred and twenty nine women accepted and used modern contraceptive methods in this center. Out of this number, one thousand two hundred and twenty one of this number used intrauterine device (32.0\%), 116 (30.3\%) used injectable progestogen while 930 of them chose implant, giving an uptake of $24.3 \%$ (569 were on Jadelle-uptake of $14.9 \%)$. Three hundred and fifteen used oral contraceptives (8.2\%) and 223 (5.8\%) had bilateral tubal ligation.

The mean age of users was $33.7 \pm 4.2,536(94.2 \%)$ were multipara with a mean parity of $4.5 \pm 3.8$ while 541 (95.1\%) had secondary education and above (Table 1). Increasingly greater number of acceptors was recorded in the later half of the study, between 2012 and 2017 (Table 2). Source of information was mainly through clinic personnel $276(48.5 \%)$ and friends and relations 233 (40.0\%) while media contributed only $33(5.8 \%)$ self referral was 27 (4.7\%). The major side effect was irregular vaginal bleeding 36 (60.9\%), weight gain was $3(5.1 \%)$; Table 3. The main reason for the implant removal was expiration of method $272(53.9 \%)$ and discontinuation due to complication was only 54 (10.3\%); Table 4. Pearl index was 0.002 from one pregnancy recorded within the period of study. Jadelle use was almost same for spacing and limiting of children (273 and $296-48 \%$ and $52 \%$ respectively).

\section{Discussion}

There were 569 (14.9\%) acceptors of Jadelle out of the 3,849 women who accepted and used contraception in this centre during the study period. The uptake of $14.9 \%$ for Jadelle alone demonstrated and increasing acceptance when compared with $15.8 \%$ for implants generally in a previous study on progestogen 
only injectable contraceptives [15] [16]. Apart from year 2014 that witnessed prolonged industrial action in this hospital, there was a progressive yearly increase in uptake of Jadelle in the lower half of the study period.

The socio demographic characteristics of users of implant in various studies are similar [17] [18]. They are young enlightened women, hence a possibly better follow up. Clinic personnel and friends and relations (88.5\%) have remained the main source of information in all studies, media accounting for appalling rate of

Table 1. Socio demographic characteristics of Jadelle acceptors.

\begin{tabular}{ccc}
\hline Age(years) & Frequency & Percentage (\%) \\
\hline $20-24$ & 16 & 2.8 \\
$25-29$ & 89 & 15.6 \\
$30-34$ & 223 & 39.2 \\
$35-39$ & 165 & 29.0 \\
40 and above & 76 & 13.4 \\
Total & 569 & $100 \%$ \\
Parity & & \\
Nulliparity & 4 & 0.7 \\
Primiparity & 29 & 5.1 \\
multiparity & 536 & 94.2 \\
Total & 569 & $100 \%$ \\
Education & & $100 \%$ \\
Primary & 28 & 4.9 \\
Secondary & 200 & 35.1 \\
Tetiary & 341 & 60.0 \\
Total & & \\
& 569 & \\
\hline
\end{tabular}

Table 2. Yearly distribution of Jadelle acceptors.

\begin{tabular}{ccc}
\hline Year & No. & Percentage (\%) \\
\hline March 2007 - Feb. 2008 & 63 & 11.1 \\
March 2008 - Feb.2009 & 44 & 7.7 \\
March 2009 - Feb.2010 & 47 & 8.3 \\
March 2010 - Feb.2011 & 45 & 7.9 \\
March 2011 - Feb.2012 & 36 & 6.3 \\
March 2012 - Feb.2013 & 62 & 10.9 \\
March 2013 - Feb.2014 & 61 & 10.7 \\
March 2014 - Feb.2015 & 45 & 7.9 \\
March 2015 - Feb.2016 & 100 & 19.6 \\
March 2016 - Feb.2017 & 66 & 11.6 \\
Total & 569 & $100 \%$ \\
\hline
\end{tabular}


Table 3. Complications of Jadelle contraceptive.

\begin{tabular}{ccc}
\hline Side effects & Frequency & Percentage (\%) \\
\hline Spotting & 16 & 27.1 \\
Amenorrhea & 10 & 16.9 \\
Menorrhagia & 10 & 16.9 \\
Headache & 9 & 15.3 \\
Weight gain & 3 & 5.1 \\
Cervical erosion & 3 & 5.1 \\
Increased blood pressure & 3 & 5.1 \\
Breast tenderness & 3 & 5.1 \\
Varicose-vein & 2 & 3,4 \\
Total & 59 & $100 \%$ \\
\hline
\end{tabular}

Table 4. Reasons for Removal of Jadelle contraceptive.

\begin{tabular}{ccc}
\hline Reasons & Frequency & Percentage (\%) \\
\hline Expiration & 299 & 56.9 \\
Desire for pregnancy & 98 & 18.7 \\
Menopause & 66 & 12.6 \\
Complications & 54 & 10.3 \\
Client request & 8 & 1.5 \\
Total & $\mathbf{5 2 5}$ & $\mathbf{1 0 0 \%}$ \\
\hline
\end{tabular}

5.8\% [16] [17] [18]. Of the 569 clients on Jadelle, only 59 had side effects and of these, spotting per vaginam, menopause, and amenorrhea topped the complications. This is in keeping with complications of all progestogens only contraceptives [19] [20] [21] [22]. It then means that this main drawback of all progestogens only contraceptives still persists. The complaint on weight gain, though not proven [23] [24] is of concern.

Other complications such as occurrence of ovarian cyst in users though common was not documented in this study but are found to be transient [25]. It is equally noted that not all complications warranted discontinuation of the device. More importantly, most of this side effects especially the relatively common one which is irregular vagina bleeding usually remits within four months in early use and also on medication [26] [27]; meaning that it is a safe means of contraception [28] [29]. More than half (56.9\%) of the removal of the implant were due to expiration hence reinsertion. Its discontinuation due to complications occurred in $10.3 \%$ of users. This is however lower than $19 \%$ found in Zaria study [30]. It also support the evidence that discontinuation due to complication is higher in Implanon than in Jadelle [30] [31].

Pearl index of jadelle was 0.002 and hence it is a very effective Contraceptive [28] [29]. Generally, long acting reversible contraceptives' higher continuation 
rate encourages superior protection from unintended pregnancies [18] [32] [33] [34]. Forty four of the users (7.7\%) were lost to follow up and must have obtained care in the other numerous primary health care centres in the city. Unlike Implanon, Jadelle is almost equally used for limiting as in spacing children (52\% and $48 \%$ respectively).

In conclusion, Jadelle has amazing protection against unintended pregnancy, good safety profile, and increasing acceptance among our clients.

\section{References}

[1] United Nations (2017) Department of Economic and Social Affairs, Population division. World Population prospects: the 2015 Revision. New York: United Nations. https://esa.un.org/unpd/wpp/publications/files/key Findings WPP 2015.pdf

[2] United Nations (2017) World Population Prospects: The 2012Rion. http://esa.un.org/unpd/wpp/index.htm

[3] National Population Census (2006) National Population Commission, Nigeria.

[4] United Nations (2017) Millennium Development Goals Report 2014. http://mdgs.un.org/unsd/mdg/default.aspx

[5] National Population Commission (2016) Nigeria's Population Now 182 Million.

[6] Eyo, E.O. and Ogu, U.I. (2015) Environmental Implication of Overpopulation and Rural Urban Migration on Development in Nigeria. Academic Research International, 4, 55 .

[7] United Nations Economic Report (2010) www.unctad.org

[8] United Nations (2017) United Nations Population Division: World Population plan of Action. UNPD. http://un.org/popin/icpd/conference/bkg/wppa.html

[9] Ladapo, O.A. and Akinso, S.A. (2005) Contraceptive Implants. African Journal of Reproductive Health, 9, 16-23. https://doi.org/10.2307/3583156

[10] Power, J., French, R. and Cowan, F.M. (2007) Subdermal Implantable Contraceptives versus Other Forms of Reversible Contraceptives or Other Implants as Effective Methods of Preventing Pregnancy. Cochrane Database of Systematic Reviews, 2007, Article ID: No.:CD001326.

[11] Hohmann, H. and Creimum, M. (2007) The Contraceptive Implant. Clinical Obstetrics and Gynecology, 50, 907-917. https://doi.org/10.1097/GRF.0b013e318159c2f6

[12] World Health Organization (2003) Contraceptive Implants Has Come of Age. www.who.htm.reproductive-health/hrp/progress/61/news61.htm

[13] Monjok, E., Smesny, A., Ekabua, J.E. and Essien, E.J. (2010) Contraceptive Practices in Nigeria: Literature Review and Recommendation for Future Policy Decisions. Open Access Journal of Contraception, 2010, 9-22.

[14] Aisien, A.O. (2007) Contraception with Levonorgestrel Subdermal Implants (Norplant $^{R}$ ) in Benin-City, Nigeria: A 12-Year Review. African Journal of Reproductive Health, 11, 90-97. https://doi.org/10.2307/30032491

[15] Ojule, J.D. and Oranu, E.O. (2017) Clinical Experience with Progestogen only Injectable Contraceptive in a Tertiary Institution in Southern Nigeria: A Ten Year Review. East African Medical Journal, 94, 14-19.

[16] Oranu, E.O., Ojule, J.D. and Orazulike, N.C. (2017) Associated Factors in the Declining Trend in the Use of Progestogen only Injectable Contraceptive in a Niger Delta University Teaching Hospital, Nigeria. Asian Journal of Medicine and Health, 


\section{3, 1-8. https://doi.org/10.9734/AJMAH/2017/32120}

[17] Pan, V.C., Mutihir. J.T., Nyang, D.D., Shambe, I., Egbodo, C.O. and Karshima, J.A. (2016) Sociodemographic Profile and Use-Dynamics of Jadelle (Levonogestrel) Implant in Jos Nigeria. Nigerian Medical Journal, 57, 314-318. https://doi.org/10.4103/0300-1652.193855

[18] Ojule, J.D., Oranu, E.O. and Enyindah, C.E. (2012) Experience with Implanon in Southern Nigeria. Journal of Medicine and Medical Sciences, 3, 710-714.

[19] Newton, V.L. and Hoggart, L. (2015) Hormonal Contraceptives and Regulation of Menstruation: A Study of Women's Attitude toward "Having Period". BMJ Sexual \& Reproductive Health, 41, 210-215. https://doi.org/10.1136/jfprhc-2014-100956

[20] Zigleer, R.E. and McNicholas, C. (2017) Unscheduled Vagina Bleeding with Progestogen-Only Contraceptive Use. American Journal of Obstetrics \& Gynecology, 216, 443-450. https://doi.org/10.1016/j.ajog.2016.12.008

[21] Weisberg, E., Bateson, D., McGreechan, K. and Mohalatra, L. (2014) A 3-Year Comparative Study of Discontinuation Rate, Bleeding Pattern and Satisfaction in Australian Women Using Contraceptive Implant or Progestogen Releasing-Intrauterine System. The European Journal of Contraception \& Reproductive Health Care, 19, 5-14. https://doi.org/10.3109/13625187.2013.853034

[22] Oranu, E.O., Ojule, J.D. and Okpani, J.O. (2016) Review of Contraceptive with Depot Medroxyprogesterone Acetate at the University of Port Harcourt Teaching Hospital, Port Harcourt, Southern Nigeria. British Journal of Medicine and Medical Research, 15, 1-6. https://doi.org/10.9734/BJMMR/2016/26504

[23] Vickery, Z., Madden, T., Zhao, Q., Seura, G., Allsworth, J. and Peipert, J. (2013) Weight Changes at 12 Months in Users of 3 Contraceptive Methods. Contraception, 88, 503-508. https://doi.org/10.1016/j.contraception.2013.03.004

[24] Lopez, L.M., Edeiman, A. and Chen, M. (2013) Progesterone only Contraceptives: Effects on Weight. Cochrane Data Base Systematic Review, 7, CD008815.

[25] Hidalgo, M.M., Lisondo, C.C., Teatin, J., Ximena, E., Elza, M., Bahamandes, L., et al. (2006) Ovarian Cyst in Users of Implanon and Jadelle Subdermal Contraceptive Implant. Contraception, 73, 532-536.

https://doi.org/10.1016/j.contraception.2005.12.012

[26] Hou, M.M., McNicholas, C. and Creinin, M.D. (2016) Combined Oral Contraceptive Treatment for Bleeding Complaints with Etonogestrel Contradeptive Implant: A Randomized Control Trial. The European Journal of Contraception \& Reproductive Health Care, 21, 361-366. https://doi.org/10.1080/13625187.2016.1210122

[27] Friedlander, E. (2015) Therapeutic Options to Unscheduled Vagina Bleeding Associated with Long-Acting Reversible Contraception. Obstetrics and Gynecology Clinics of North America, 42, 593-603. https://doi.org/10.1016/j.ogc.2015.07.004

[28] Laphikanont, W. and Taneepanichskul, S.V. (2006) Effects of Jadelle Use in Thai Women Aged 20 and 45 Years in Kug Chulangkorn Memorial Hospital. Journal of the Medical Association of Thailand, 89, 761-766.

[29] Steiner, M.J., Lopez, L.M., Grimes, D.A., Cheng, L., Shelton, J., Trussell, J., Farley, T.M. and Dorflinger, L. (2010) Sino-Implant (11)-A Levenogestrel Releasing Two-Rod Implant: Systematic Review of Randomized Control Trial. Contraception, 81, 197-210.

[30] Madugu, N.H., Abdyl, M.A., Bana, U. and Kolawole, B. (2015) Uptake of Home Implant Contraceptive in Zaria, Northern Nigeria. Journal of Obstetrics and Gynaecology, 5, 268-273. 
[31] Rowlands, S. and Searle, S. (2014) Contraceptive Implants: Current Perspectives. Open Access Journal of Contraceptives, 5, 73-84.

[32] Hubacher, D. (2017) LARC Acceptability and Unintended Pregnancy among Women Presenting for Short Acting Methods: A Randomized Patients Preference Trial. American Journal of Obstetrics \& Gynecology, 216, 101-109.

[33] Haddad, L., Wall, K.M., Vwalika, B., Khu, N.H., Brill, I., Kilembe, W. et al. (2013) Contraceptive Discontinuation and Switching among Couples Receiving Integrated HIV and Family Planning Services in Lusaka, Zambia. AIDS, 27, S93-S103. https://doi.org/10.1097/QAD.0000000000000039

[34] Zoul, M. and LARC Guideline Development Group (2008) The Cost-Effectiveness of Long-Acting Reversible Contraceptive Methods in UK: Analysis Based on a Decision-Analytic Model Developed for a National Institute for Health and Clinical Excellence (NICE) Clinical Practice Guideline. Human Reproduction, 23, 1338-1345. 